\title{
PRODUCTION OF 316L STAINLESS STEEL (SS316L) FOAM VIA SLURRY METHOD
}

\author{
N. I. Mad Rosip ${ }^{1}$, S. Ahmad ${ }^{1}$, K. R. Jamaludin' ${ }^{2}$ and F. Mat Noor ${ }^{1,2}$ \\ ${ }^{1}$ Faculty of Mechanical and Manufacturing Engineering, \\ University Tun Hussein Onn Malaysia, 86400 Batu Pahat, Johor. \\ ${ }^{2}$ Academic Manager (Graduate Studies) \\ UTM Razak School of Engineering and Advanced Technology \\ Level 7, Razak Tower, Universiti Teknologi Malaysia Kuala Lumpur \\ 54100 Jalan Semarak, Kuala Lumpur. \\ Email: nooridayu.mr@gmail.com
}

\begin{abstract}
Metal foams are a special class of porous materials with novel physical, mechanical, thermal, electrical and acoustic properties. Nowadays, 316L stainless steel (SS316L) foam is considered as one of the attractive metallic materials for biomedical applications due to its excellent mechanical properties, biocompatibility, and corrosion resistance. In this study, SS316L has been used to produce metal foams using the slurry method. The compositions of the SS316L metal powder were $40 \mathrm{wt} \%$ and $60 \mathrm{wt} \%$, PEG (3 wt \%), CMC (3 wt \%) with the remainder distilled water. Polyethylene glycol (PEG) and methylcellulose (CMC) were used as a binder. The raw materials were mixed using a ball milling machine. After that, the polyurethane (PU) foams were immersed in the mixture then dried in the oven for 24 hours. Then, the samples were sintered in a box furnace at $1300^{\circ} \mathrm{C}$. In order to characterize the samples, several tests were conducted such as x-ray diffraction (XRD), energy diffraction x-ray (EDX), and morphological analysis (optical microscopy and scanning electron microscopy (SEM)). The most suitable composition of SS316L is $60 \mathrm{wt} \%$ with a sintering temperature of $1300^{\circ} \mathrm{C}$ which resulted in large-pored metal foam. The SS316L metal foams were successfully produced using the slurry method. However, the quality of the SS316L metal foam must be improved because it had too low a strength to undergo mechanical testing.
\end{abstract}

Keywords: Metal foam; stainless steel; slurry method; ball milling.

\section{INTRODUCTION}

In recent years, metal foams have been the subject of study by a number of researchers. Various types of metals have been reviewed as the main materials in producing metal foams. Titanium, titanium alloys, nickel, aluminum and stainless steel were often the focus of researchers (Altieri, Flores, Gonzalez, \& Rodríguez, 2003; Michailidis, Stergioudi, Tsouknidas, \& Pavlidou, 2011);. Metal foams are also known as porous metallic products which have good properties such as low density and high specific surface area (Omar, Papadopoulos, Tsipas, \& Lefakis, 2009). Other than that, metal foams have a cellular structure which possesses high strength and stiffness, high impact energy, fire retardation and heat dissipation properties(Vendra \& Rabiei, 2007). In the mainstream of current sophistication, modern equipment has undergone extensive development in biomedical applications. Already, stainless steel has been reviewed for use as implants in the human body(Hermawan, Ramdan, \& Djuansjah, 2011). Various 
types of metal have been used in biomedical applications depending on the specific implant requirement (Hermawan et al., 2011). Stainless steel 316L (SS316L) has been widely used in fields ranging from cardiovascular to otorhinology and also dental. SS316L has been used for cardiovascular stent implants, prostheses, orthopaedic bone fixation implants and orthodontic wires in dentistry. This type of alloy has become known in the production of biomedical applications because of its good mechanical properties and excellent corrosion resistance (Ding, Wang, Li, \& Zheng, 2010; Hermawan et al., 2011; Roguska et al., 2011). Open cell foams based on polyurethane (PU) foam have been made using the slurry method (Quadbeck et al., 2011). Because of their good physical and mechanical properties together with their biocompatibility characteristics, polyurethanes (PUs) are used widely in biomedical applications such as heart valves, aortic grafts, and dialysis membranes, pacing leads insulation, indwelling catheters, intra-aortic balloons and mammary implants(Wadley, 2002). In this study, PU foams have been used as scaffolds. In addition, PEG and CMC binders, which are water soluble materials, have also been used in the slurry (Ahmad et al., 2010).

In the world of emerging technology, there are various types of metal foam in production. Several methods can be considered to produce porous metallic foam by using metal powder, such as the 'Fraunhofer Process', gas entrapment and foaming of slurries (Banhart \& Baumeister, 1998). One of the commonly used methods to produce metal foam by powder metallurgy is the slurry method. This method is usually used for producing metal foam by providing a metal powder, blowing agent and a binder. The metal powder, blowing agent and binder are mixed then poured into a mold, and the mixture is left while the temperature is elevated to melting temperature. The binder and blowing agent affect the slurry, so that it becomes viscous and expands. Researchers have succeeded in producing metallic foam via the slurry method to produce many types of steels, titanium alloys, and also open-cell molybdenum for various applications (Quadbeck et al., 2011). In addition, others have studied aluminizing nickel foam by a slurry coating process and have succeeded in coating nickel with aluminium (Omar et al., 2009). The final process in producing SS316L foam is sintering. The author has reported that there are two types of sintering, namely solid state sintering and liquid phase sintering. Solid state sintering occurs when the compaction density is increased while it is at the fully solid state sintering temperature ((Ahmad et al., 2010). Liquid phase sintering occurs when there is liquid in the compaction during the sintering process(Quadbeck et al., 2011). The main objective of this research is to investigate the physical properties of metal foams with different compositions of SS316L powder.

\section{EXPERIMENTAL PROCEDURES}

The material used in this study was SS316L powder which was mixed with the binder and forming agent before being milled using a ball mill to become slurry. The compositions that were used to produce the slurry were $40 \mathrm{wt} \%$ and $60 \mathrm{wt} \%$ of SS316L, $3 \mathrm{wt} \% \mathrm{CMC}$ and PEG with distilled water as the remaining percentage. The powders were milled with a ball charge ratio of 5:1 at a rotation speed of $150 \mathrm{rpm}$ for 2 hours. PU foams were soaked in the slurry for 15 minutes and the slurry was absorbed into the foam accordingly. The excess slurry was squeezed out then the foams were immersed again in the slurry. This was purposely done to ensure that the slurry attached to every pore and strut of the PU foams. After that, the foams were dried in the oven for 24 hours at $30^{\circ} \mathrm{C}(\mathrm{Ahmad}$ et al., 2010). The drying process was necessary to eliminate the low viscosity liquid from the foams. Then, after the drying process, the foams were 
sintered in a box furnace to produce bonding between the melted powder particles and to increase the strength and hardness of the mechanical properties. The sinter temperature applied was $1300^{\circ} \mathrm{C}$, at which temperature the metal powder molecules should bond with each other to form strong metal foam. Besides, the PU foam should be decomposed as well as the binders.

\section{RESULTS AND DISCUSSION}

A number of tests were carried out on samples of the SS316L metal foam, namely x-ray diffraction (XRD) analysis, energy diffraction x-ray (EDX) analysis and morphology tests (optical microscopy and scanning electron microscopy (SEM)). XRD analysis is a non-destructive technique that was used to identify the elements found in the SS316L metal foam. Table 1 shows the results obtained from EDX testing of SS316L metal foam containing $40 \mathrm{wt} \%$ and $60 \mathrm{wt} \% \mathrm{SS} 316 \mathrm{~L}$ and also raw material of SS316L. From this table, it can be seen that $\mathrm{Fe}$ is present with the highest percentages in the SS316L metal foams $(69.58 \%, 54.65 \%$ and $49.19 \%)$, followed by $\mathrm{O}, \mathrm{Cr}$ and $\mathrm{Ni}$. Indeed, these elements are present in SS316L powder before it is mixed with the binders and PU foam. In addition, from this result it can be said that the binders and PU foam were fully decomposed because none of these materials were found during the XRD and EDX analysis. However, the high content of O $(18.84 \%, 18.95 \%$ and $23.12 \%)$ in the SS316L metal foams showed that the oxidation happened during the sintering process.

Table 1. EDX results for raw SS316L powder and SS316L metal foam.

\begin{tabular}{cccc}
\hline Element & Raw SS316L & $\begin{array}{c}\text { 40wt\% SS316L } \\
\text { Mass \% }\end{array}$ & 60wt\% SS316L \\
\hline $\mathrm{O}$ & \multirow{3}{*}{18.84} & 18.95 & 23.12 \\
$\mathrm{Cr}$ & & 16.60 & 7.71 \\
$\mathrm{Fe}$ & 69.58 & 54.65 & 49.19 \\
$\mathrm{Ni}$ & 9.58 & 9.80 & 19.94 \\
\hline
\end{tabular}

Figure 1 shows the XRD results before and after the sintering process following the pattern of JCPDS 03-065-5131, which was iron nickel $\left(\mathrm{Fe}_{3} \mathrm{Ni}_{2}\right)$. The highest intensity value for 2-theta at 43.532 is based on JCPDS 03-065-5131. Based on the graph, $40 \mathrm{wt} \%$ SS316L (JCPDS 01-089-8104) which was iron oxide $\left(\mathrm{Fe}_{2} \mathrm{O}_{3}\right)$, also called hematite, and $60 \mathrm{wt} \%$ SS316L (JCPDS 01-089-8104) show similar peaks. However, the peaks were different from those for the raw SS316L. This was because the SS316L metal foams were oxidized during the sintering process(Upadhyaya, 2000). The presence was also detected of iron $(\mathrm{Fe})$, nickel $(\mathrm{Ni})$, chromium $(\mathrm{Cr})$ and oxygen $(\mathrm{O})$. These elements form compounds that are present in the SS316L metal foam such as the hematite $\left(\mathrm{Fe}_{2} \mathrm{O}_{3}\right)$. The existence of elements in the SS316L metal foam were further strengthened with the EDX results which confirmed the presence of the elements $\mathrm{Fe}, \mathrm{Ni}$, $\mathrm{Cr}$ and $\mathrm{O}$ in the metal foams produced. 


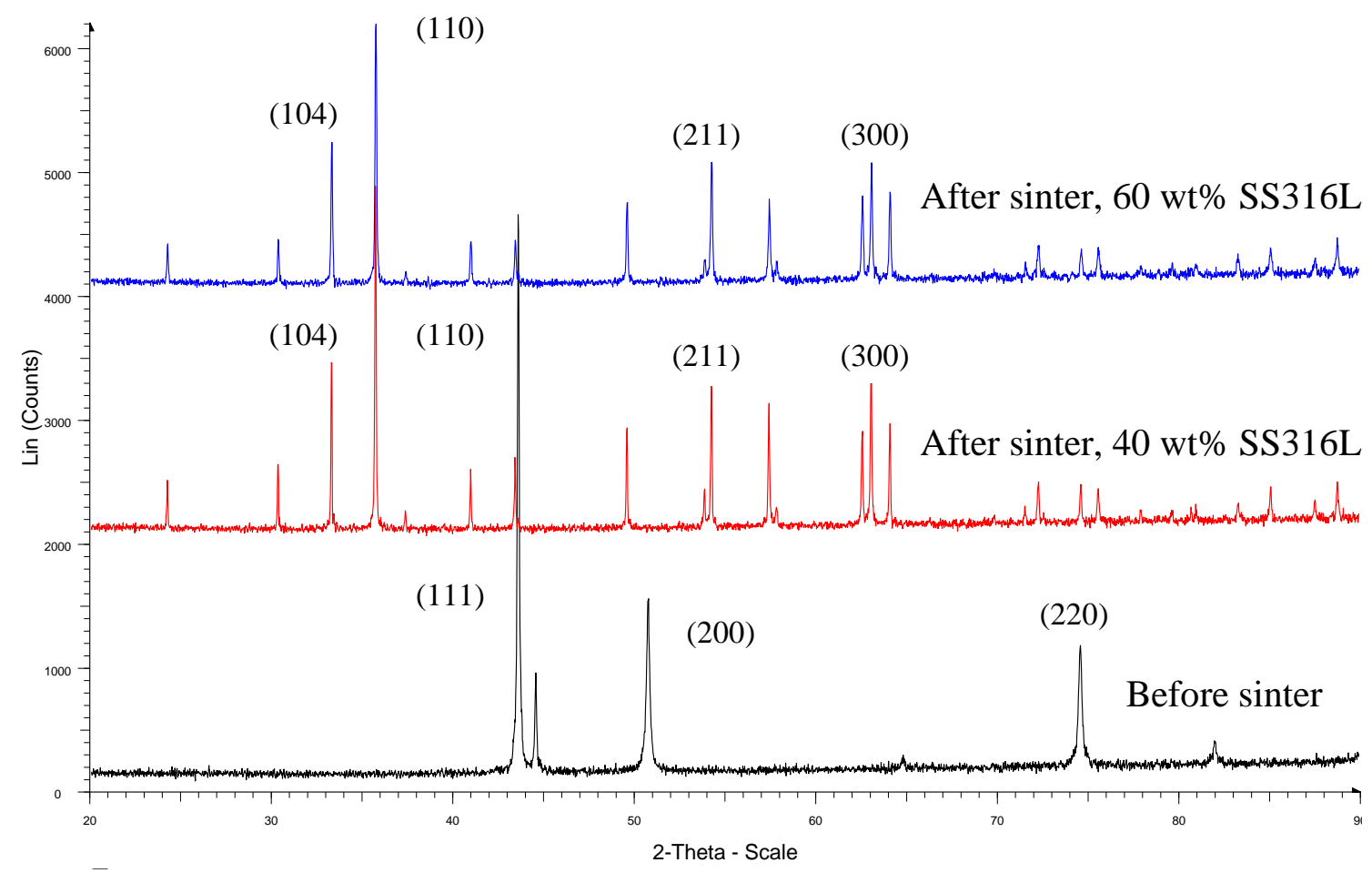

Figure 1. Results of X-ray diffraction (XRD) analysis.

Next, Figure 2 shows the SEM test results of SS316L metal foams for $40 \mathrm{wt} \%$ and $60 \mathrm{wt} \%$ SS316L with $\times 30$ and x1500 magnification. Observation of Figure 2 (a) and (b), which are images of the $40 \mathrm{wt} \% \mathrm{SS} 316 \mathrm{~L}$, shows more closed pores than open pores. In other words, while the SS316L metal foam did not shrink, it showed low mechanical strength. Figure 2 (b) shows the micro pores which occurred in large numbers and size because the coarsening of particles did not happen(German, 1996). Besides, a few powder particles seemed to change shape as if responding to the sintering process. Figures 2 (c) and (d) show that better pores were produced in the $60 \mathrm{wt} \%$ than in the $40 \mathrm{wt} \% \mathrm{SS} 316 \mathrm{~L}$ metal foam. The metal foam samples containing $60 \mathrm{wt} \% \mathrm{SS} 316 \mathrm{~L}$ also did not shrink. However, they also had more closed pores than open pores, although the number was less than the closed pores found in $40 \mathrm{wt} \% \mathrm{SS} 316 \mathrm{~L}$ metal foam. This was because the powder particles did not combine well with each other and the neck growth did not happen during the sintering process. So, elimination of the pores did not occur (German, 1996). In other words, the SS316L powder particles changed to an irregular shape. This shows that the SS316L metal foams were successfully produced using the slurry method, although they still needed to be improved in order to undergo mechanical testing. 


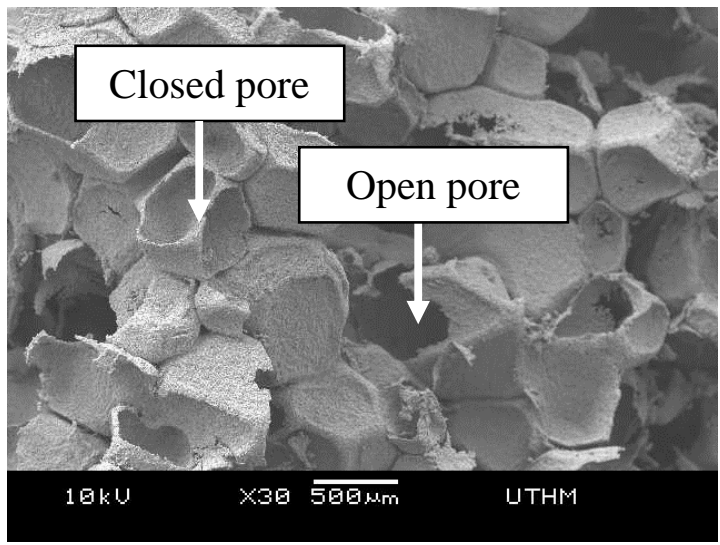

(a)

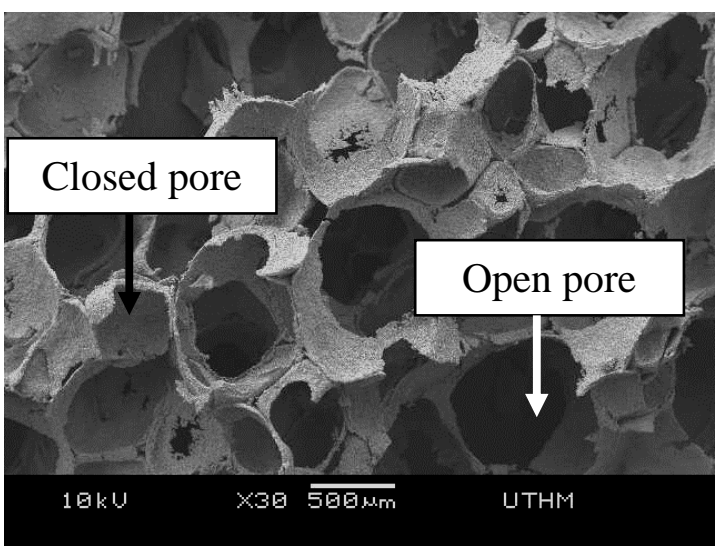

(c)

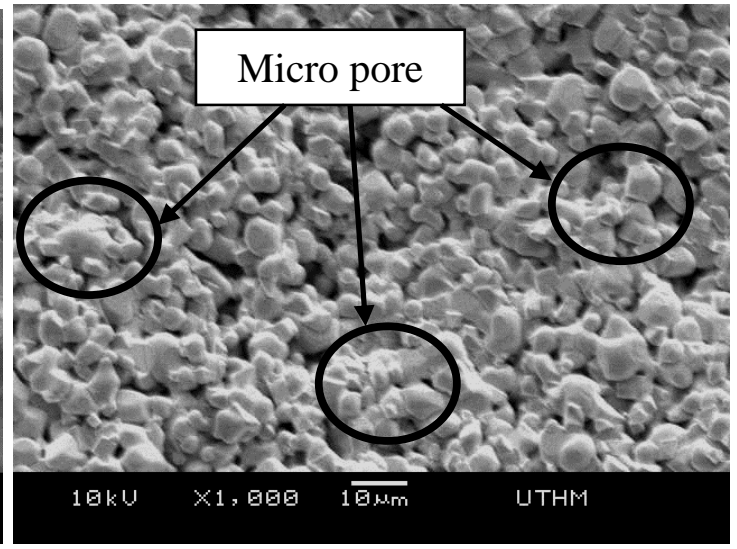

(b)

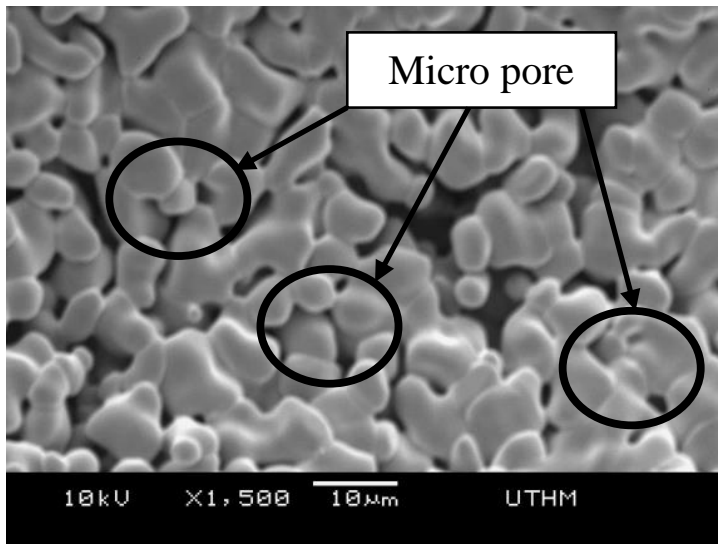

(d)

Figure 2. SEM test results of SS316L metal foams for $40 \mathrm{wt} \%(\mathrm{a}, \mathrm{b})$ and $60 \mathrm{wt} \%(\mathrm{c}, \mathrm{d})$ SS316L at x30 and x1500 magnification.

\section{CONCLUSIONS}

SS316L metal foams were successfully produced using the slurry method. However, the quality of the SS316L metal foam must be improved because its strength was too low to undergo mechanical testing. The XRD and EDX results showed that the samples after sintering were oxidized. In addition, the SEM diagrams showed that the metal foams had more closed pores than open pores and that the powder particles did not grow well enough to combine with each other. Hence, a finding of this study is that the metal foam should have open pores. Some improvements might help to further improve this study. Increasing the temperature of the sintering process would help the SS316L powder molecules to grow and combine with each other, and the sintering process should ideally be done in a vacuum furnace to avoid oxidation. Other than that, it would be desirable to have extra time to soak the PU foams in the SS316L slurry and then to squeeze them to ensure that the solution is completely absorbed into each of the PU foam's pores and struts. 


\section{ACKNOWLEDGEMENT}

This research was funded under the "Graduate Incentive Scheme" program of the Office for Research, Innovation, Commercialization and Consultancy Management, Universiti Tun Hussein Onn Malaysia. The authors would also like to thank the Malaysian Ministry of Education for the financial support through the Exploration Research Grant Scheme (ERGS-E028).

\section{REFERENCES}

Ahmad, S., Muhamad, N., Muchtar, A., Sahari, J., Ibrahim, M., Jamaludin, K., \& Nor, N. (2010). Development and characterization of titanium alloy foams. International Journal of Mechanical and Materials Engineering (IJMME), 5(2), 244-250.

Altieri, C., Flores, J., Gonzalez, V., \& Rodríguez, A. (2003). Biomechanics of orthopaedic fixations.

Banhart, J., \& Baumeister, J. (1998). Production methods for metallic foams. Paper presented at the MRS Proceedings.

Ding, M. H., Wang, B. L., Li, L., \& Zheng, Y. F. (2010). Preparation and characterization of tacxn1\&\#xa0;-\&\#xa0;x coatings on biomedical 3161 stainless steel. Surface and Coatings Technology, 204(16-17), 2519-2526.

German, R. M. (1996). Sintering theory and practice. Sintering Theory and Practice, by Randall M. German, pp. 568. ISBN 0-471-05786-X. Wiley-VCH, January 1996., 1.

Hermawan, H., Ramdan, D., \& Djuansjah, J. R. P. (2011). Metals for biomedical applications.

Michailidis, N., Stergioudi, F., Tsouknidas, A., \& Pavlidou, E. (2011). Compressive response of al-foams produced via a powder sintering process based on a leachable space-holder material. Materials Science and Engineering: A, 528(3), 1662-1667.

Omar, H., Papadopoulos, D. P., Tsipas, S. A., \& Lefakis, H. (2009). Aluminizing nickel foam by a slurry coating process. Materials Letters, 63(16), 1387-1389.

Quadbeck, P., Kümmel, K., Hauser, R., Standke, G., Adler, J., Stephani, G., \& Kieback, B. (2011). Structural and material design of open-cell powder metallurgical foams. Advanced Engineering Materials, 13(11), 1024-1030.

Roguska, A., Hiromoto, S., Yamamoto, A., Woźniak, M. J., Pisarek, M., \& Lewandowska, M. (2011). Collagen immobilization on 3161 stainless steel surface with cathodic deposition of calcium phosphate. Applied Surface Science, 257(11), 5037-5045.

Upadhyaya, G. S. (2000). Sintered metallic and ceramic materials: Preparation, properties and applications: Wiley.

Vendra, L. J., \& Rabiei, A. (2007). A study on aluminum-steel composite metal foam processed by casting. Materials Science and Engineering: A, 465(1-2), 59-67.

Wadley, H. N. G. (2002). Cellular metals manufacturing. Advanced Engineering Materials, 4(10), 726-733. 